\title{
CRIANÇA E TECNOLOGIA: NOVAS EXPERIÊNCIAS DA INFÂNCIA
}

\author{
Ana Lívia E. F. Gonçalves ${ }^{1}$ \\ Yuri Toledo Kuwahara ${ }^{2}$ \\ Luiz Antonio Feliciano ${ }^{3}$
}

Resumo: As experiências, na contemporaneidade, ganharam novas roupagens, novas relações, novos jogos, novas interações, novos condicionamentos. A tecnologia tem um papel fundamental nessas alterações, sobretudo, aquelas relacionadas com a produção de imagem e difusão de informação. Diante desse cenário, como se configuram as experiências da infância na atualidade, pois é uma geração que nasce incorporada às novas tecnologias digitais? Dessa forma, problematizar as experiências da infância, a partir da inserção da imagem na sua cotidianidade se configurou o objetivo geral do trabalho. Mapear os tipos de brincadeiras mais aceitas pelas crianças atualmente, possibilitar um contato maior com universo da fotografia e discutir a interferência da imagem fotográfica na relação da criança com o mundo compuseram os objetivos específicos. Um estudo antropológico, amparado pelo método etnográfico, dentro de uma sala de aula da de $3^{\circ}$ ano do ensino fundamental, do Instituto Santa Teresa, foi o caminho para alcançar tais objetivos.

Palavras-chave: Infância; Experiência; Novas tecnologias; Subjetividade; Escola.

\footnotetext{
${ }^{1} 2^{\circ}$ Ano Ensino Médio IST/ISPIC/UniFatea, Brasil. E-mail: anaespindula99@gmail.com.

2 Pedagogia IST/UniFatea, Brasil. E-mail: yuri.toledo.kuwahara@hotmail.com.

3 Publicidade e Propaganda ISPIC/UniFatea, Brasil. E-mail: luizliu@yahoo.com.br.
} 